\title{
Measuring geospatial healthcare access to primary level facilities in Mexico: a GIS-based diagnosis analysis
}

\author{
Medindo o acesso geoespacial da assistência médica a instalações \\ de nível primário no México: uma análise de diagnóstico baseada \\ em sistemas de informação geográfica
}

Daniel Choperena-Aguilar (https://orcid.org/0000-0003-2582-5511) ${ }^{1}$

Andrea Ramirez-Santiago (https://orcid.org/0000-0002-6201-1907) ${ }^{2}$

María Cecilia Acuña Díaz (https://orcid.org/0000-0001-9576-5791) ${ }^{3}$

${ }^{1}$ Facultad de Ciencias Políticas y Sociales. Circuito Mario de la Cueva S/N, Ciudad Universitaria. 04510 Alcaldía Coyoacán Ciudad de México México. danielchoperena@ politicas.unam.mx ${ }^{2}$ Instituto Nacional de Estadística y Geografía. Ciudad de México México. ${ }^{3}$ Organización Panamericana de la Salud/ Organización Mundial de la Salud. Ciudad de México México.

\begin{abstract}
To describe a general overview of health services delivery in Mexico and geospatially analyze the current distribution and accessibility of Primary Health Care (PHC) facilities to contribute to new approaches to improve healthcare planning in Mexico. We performed a spatial analysis of official data to analyze current distances from health facilities to population, to determine the underserved areas of health services delivery in three selected states using a ranking of indicators. We estimated service area coverage of PHC facilities with road networks of three Mexican states (Chiapas, Guerrero, and Oaxaca). Our estimations provide an overview of spatial access to healthcare of the Mexican population in Mexico's three most impoverished states. We did not consider social security nor private providers. Geospatial access to health facilities is critical to achieving PHC and adequate coverage. Countries like Mexico must measure this to identify underserved areas with a lack of geospatial access to healthcare to solve it. This type of analysis provides critical information to help decision-makers decide where to build new health facilities to increase effective geospatial access to care and to achieve Universal Health Coverage.

Key words Mexico, Geographic Information Systems, Primary Healthcare, Spatial Analysis, Network analysis
\end{abstract}

Resumo Descrever uma visão geral da prestação de serviços de saúde no México e analisar geoespacialmente a atual distribuição e acessibilidade das unidades de APS para contribuir com novas abordagens para melhorar o planejamento da saúde no México. Realizamos uma análise espacial de dados oficiais para analisar as distâncias atuais das unidades de saúde à população, para determinar as áreas descobertas de prestação de serviços de saúde em 3 estados selecionados usando uma classificação de indicadores. Estimamos a cobertura da área de serviço das unidades de APS com redes viárias de 3 estados do México (Chiapas, Guerrero e Oaxaca). Nossas estimativas fornecem uma visão geral do acesso espacial à saúde da população mexicana nos três estados mais pobres do México. Não consideramos seguridade social nem prestadores privados. O acesso geoespacial às unidades de saúde é fundamental para alcançar a cobertura universal de saúde e uma cobertura eficaz. Países, como o México, devem medir isso para identificar áreas não merecidas com falta de acesso geoespacial à saúde para resolvê-lo. Os governos devem gerar políticas e mecanismos para distribuir efetivamente novas instalações de saúde para aumentar o acesso geoespacial efetivo à saúde, bem como para evitar instalações de saúde não planejadas.

Palavras-chave México, Sistemas de Informação Geográfica, Atenção Primária à Saúde, Análise espacial, Análise de rede 


\section{Introduction}

Strengthening primary health care (PHC) delivery is critical for the improvement of population health and health-system performance ${ }^{1,2}$. Travel-time (distances), ease of access to primary care services and services availability at the first level of care are major factors that influence the timely utilization of health services allowing for a reduction of the economic burden of transportation $^{3-6}$. In 2018, the Astana Declaration renewed the global leaders' commitment to strength PHC, and currently many countries recognize the key role of PHC on delivering affordable and comprehensive care with greater population coverage, producing better and more equitable health outcomes $^{7,8}$.

The distribution of population in Mexico shows striking contrasts, with densely populated cities and regions along with sparsely populated areas spread out over vast territories. This situation represents a major challenge for health authorities, especially for the suitable distribution of PHC facilities to achieve Universal Health Coverage (UHC). Over the last years, the Mexican Ministry of Health has focused on improving healthcare delivery, including financing, health information systems and resource allocation. However, since there are no standardized directions on how to allocate infrastructure, human resources or medical equipment, the allocation decisions are carried out using different criteria such as local authorities' requests, the demand of health services in all health units in the state, or the population's growth; this is especially so for PHC facilities. In this article we provide a general overview of health services delivery in Mexico and a geospatial analysis of the current distribution of and accessibility to PHC facilities as an innovative approach to improve healthcare delivery planning in Mexico.

\section{Primary Healthcare Delivery in Mexico}

The Mexican Healthcare System is highly segmented and composed by several providers with little coordination among them due to legal restrictions9. The population is divided in two groups, the "insured" and the "uninsured" Affiliation to social security institutions is only available to formal or state workers; in Mexico more than $50 \%$ of people has an informal employment ${ }^{11}$. Each health provider has its own mechanism for planning new healthcare facilities. The inefficient and unintegrated informa- tion systems between providers result in duplicities on targeted population and services, as well as a lack of suitable spatial distances and services availability based on people health needs ${ }^{12}$.

The official information systems show a great number of health care facilities for most of the healthcare providers, concentrated in primary care facilities (Table 1). Military forces were excluded due to unavailability of disaggregated data.

Providers' organization of primary care services differ between them. While the Mexican Institute of Social Security (IMSS) carries out primary care (only for middle-income insured population) with family doctors (specialists) trained by the institution and offered in primary level units nestled in communities relatively close to their homes, the Ministry of Health (MoH) facilities mainly provide PHC using young doctors (recently trained without a completed degree) as a one-year social service in less developed communities (for uninsured low-income population), changing doctors each year without continuity of care, caused by a lack of investment in human resources in those facilities, building endless and undesirable inequality barriers to people's adequate access.

The responsiveness of the current care model and the random and unintegrated distribution of facilities between healthcare providers in the states have produced an ineffective healthcare system with poor health outcomes for the population. Currently, Mexico ranks first in thirty-day mortality after hospital admission due to acute myocardial infarction (AMI) based on unlinked data ${ }^{13}$ and third in Thirty-day mortality after hospital admission due to hemorrhagic stroke based on unlinked data during the period 2009-2015 among OECD Countries. Both diseases take on particular relevance (in terms of this analysis) because the time between people's location and facilities is critical to patient survival. Considering that there is no cost-effective method to increase the number of hospital-based hemodynamic units, the pharmacological management of AMI in PHC facilities provides timely reperfusion to ischemic stroke and myocardial infarction ${ }^{14,15}$.

\section{The role of GIS for planning infrastructure}

Geographic information systems (GIS) are information technologies (IT) enabling the acquisition, representation, storage, and processing of geographically referenced data. They play increasingly important roles in many fields ${ }^{16}$. 
Table 1. Distribution of Hospitals and PHC Units per provider and annual growth of PHC Units 1950-2019.

\begin{tabular}{|c|c|c|c|c|c|c|c|c|c|}
\hline \multicolumn{10}{|c|}{ Distribution of Hospitals and PHC Units per provider and annual growth of PHC Units 1950-2019 } \\
\hline \multirow{2}{*}{$\begin{array}{c}\text { Health } \\
\text { provider }\end{array}$} & \multirow[b]{2}{*}{ Hospitals } & \multirow{2}{*}{$\begin{array}{l}\text { PHC } \\
\text { units }\end{array}$} & \multicolumn{7}{|c|}{ Annual growth of PHC units } \\
\hline & & & $\begin{array}{c}1950- \\
1960\end{array}$ & $\begin{array}{c}1961- \\
1970\end{array}$ & $\begin{array}{c}1971- \\
1980\end{array}$ & $\begin{array}{c}1981- \\
2000\end{array}$ & $\begin{array}{c}2001- \\
2010\end{array}$ & $\begin{array}{c}2011- \\
2019\end{array}$ & DNA \\
\hline $\mathrm{MoH}$ & 819 & 13,921 & 276 & 859 & 1,861 & 2,390 & 3,347 & 1,643 & 3,078 \\
\hline Private services & 3,356 & 7,316 & 1 & 10 & 25 & 61 & 2,121 & 5,058 & 50 \\
\hline IMSS-Bienestar & 80 & 4,143 & 0 & 5 & 1,481 & 1,320 & 255 & 335 & 160 \\
\hline IMSS & 273 & 1,160 & 0 & 7 & 30 & 17 & 52 & 33 & 1,098 \\
\hline ISSSTE & 113 & 1,035 & 5 & 74 & 124 & 382 & 197 & 13 & 16 \\
\hline Local services & 50 & 245 & - & - & - & - & - & - & - \\
\hline PEMEX & 23 & 40 & - & - & - & - & - & 3 & 37 \\
\hline Other & 29 & 245 & - & - & - & - & - & - & - \\
\hline Total & 4,714 & 27,860 & 282 & 955 & 3,521 & 4,170 & 5,972 & 7,085 & 4,439 \\
\hline
\end{tabular}

Footnotes: We excluded 200 PHC units and 83 hospitals from military forces due to unavailable accurate disaggregated data. MoH: Ministry of Health; IMSS Bienestar: They are units which offer health services to the uninsured, mostly rural and indigenous population; IMSS: Mexican Institute of Social Security; ISSSTE: Institute of Social Security and Services for State Workers; Local services: Thirty-two decentralized public institutes without no relationship between them. They provide health services to insured people in each state. PEMEX: Mexican Petroleum Health Services; Other: Here we included Red Cross units, university-managed units, and other non-profit state-managed institutions. NAD: Data not available.

Source: CLUES Catalogue and Dynamic Cubes, Mexican Ministry of Health.

GIS effectively link and analyze data that address complex issues in health promotion, public health, community medicine and epidemiology, and in a range of other fields ${ }^{17}$.

Together with spatial analysis techniques, they can strengthen the identification of health services requirements for maternal care due to increasing fertility rate within limited influence areas ${ }^{18}$, measurements of current distances, and coverage of health services in urban and regions with low road accessibility to design alternative healthcare options and redesign the public transportation routes and schedules ${ }^{19,20}$, analysis of associations between heart diseases outcomes and access to health care services to develop strategies to improve results ${ }^{21,22}$, diagnosis of health services availability, spatial coverage of Primary Health Care units, and approaches to contribute to coping with COVID-1923 *

Geographic variation in the population, and population need for health care, provides the foundation for analysis and planning of health services. Therefore, GIS is increasingly used to explore geographical variation in the need for health services and to develop innovative indicators of health care needs ${ }^{24}$. As digital health information becomes more available, health needs data will be incorporated in GIS-based decision support tools that allow decision-makers to examine health care needs, access, and availability issues.
Access to healthcare describes people's ability to use health services when and where they are needed. It is an essential issue as many populations face substantial barriers to access. GIS creates better geographical access measures and analyzes geographical inequalities in access and social and economic pattern $s^{24}$.

\section{Methods}

As a first step, we collected the following official data (from governmental information systems):

\section{Statistical Data}

1) The 2020 National Catalogue of Health Facilities (CLUES) from the Mexican Ministry of Health ${ }^{25}$, which integrates data from the healthcare facilities like name, address, number of health facilities (PHC units and hospitals), geographic coordinates, and their unique identification key called CLUES. This catalog mainly includes public healthcare facilities, as private facilities are not a legally required for their medical units' operations. CLUES is a compulsory ID for all the Mexican healthcare facilities.

2) The National Catalogue of Health Resources of the Ministry of Health of Mexico ${ }^{26}$, to corroborate data included in CLUES catalogue (name, address, and amount of health facili- 
ties). This catalogue and CLUES catalogue independently works to collect and provide health facilities data.

3) The 2015 National Intercensal Survey from the National Institute of Statistics and Geography (INEGI) ${ }^{27}$, which collects the sociodemographic information at the national level, with a five-periodicity.

4) The 2018 Results of Multidimensional Measurement of Poverty ${ }^{28}$ from the National Council for the Evaluation of Social Development Policy (CONEVAL).

\section{Geospatial Data}

1) The INEGI 2019 National Geostatistical Framework ${ }^{29}$, which integrates geospatial information of the division of the national territory at different disaggregation levels (basic geostatistical areas or AGEB, urban and rural locations, municipalities, and states) to refer geographically the statistical information of the censuses and surveys.

2) The INEGI 2019 National Road Network $^{30,31}$, which integrates geospatial information on national communication routes, including, among its data, the road type and speed allowed.

\section{Selection of the study area}

We conducted a comprehensive analysis of the 32 states from statistical data sources to rank state-level data for selecting a study area. The variables included in the ranking were: land area $\left(\mathrm{Km}^{2}\right)$, total population, indigenous population, poverty range+, insured population (by social security institutions), health services users, number of PHC units, and hospitals.

\section{Land area}

According to INEGI, Mexico has an area of $1,961,485 \mathrm{~km}^{2}$, divided into 32 states. Five states account for more than $40 \%$ of total land area; Chihuahua $\left(247,455 \mathrm{~km}^{2}, 13.1 \%\right)$, Sonora $\left(179,355 \mathrm{~km}^{2}, 9.5 \%\right)$, Coahuila $\left(151,562 \mathrm{~km}^{2}\right.$, $8.0 \%)$, Durango $\left(123,317 \mathrm{~km}^{2}, 6.5 \%\right)$, and Oaxa$\mathrm{ca}\left(93,757 \mathrm{~km}^{2}, 5.0 \%\right)^{27,29}$.

\section{Total and indigenous population}

According to INEGI, in Mexico, 21.5\% $(25,694,928)$ of the total population identifies as indigenous. Indigenous peoples are overwhelmingly poor compared to the rest of the popu- lation. The states with the highest proportion of indigenous people are Oaxaca $(32.2 \%)$, Yucatán $(28.9 \%)$, Chiapas (27.9\%), Quintana Roo $(16.6 \%)$, and Guerrero $(15.3 \%)^{27,29}$.

\section{Poverty range}

CONEVAL categorizes people in multidimensional poverty and extreme multidimensional poverty. People in multidimensional poverty do not exercise at least one of their rights for social development, and their income is insufficient to acquire the goods and services that they require to satisfy their needs. People in extreme multidimensional poverty are those whose income is below the extreme poverty line, and they have a significant number of social deprivations per the definition of the threshold of extreme deprivation. In Mexico, the states with the highest share of people in multidimensional poverty and extreme multidimensional poverty are Chiapas (76.4\% and 29.7\%), Guerrero (66.5\% and $26.8 \%)$, and Oaxaca $(66.4 \% \text { and } 23.3 \%)^{28}$.

\section{Healthcare Services}

While health delivery in Mexico is complicated and depends on several factors, including financing barriers and the lack of collaboration between health providers, we analyze health delivery in terms of spatial access to healthcare units. We used PHC units of the Ministry of Health (which attends people with or without social security and usually does not require payment). We decided to exclude social security institutions because we do not have their disaggregated data to perform an in-depth analysis.

We decided to analyze the states with the highest proportion of users of health services of the Ministry of Health: Chiapas (82.1\%; 1,030 PHC units and 49 hospitals), Oaxaca (78.3\%; 911 PHC units and 39 hospitals), and Guerrero (77.3\%; 1,009 PHC units and 43 hospitals) ${ }^{25-27}$.

\section{Geospatial healthcare access analysis}

The "Service Areas" of the healthcare units were set at 30 minutes, 60 minutes, and 120 minutes for each selected state. This analysis was carried out using the "Network Analyst" extension of the ArcGIS software, which is based on road length and speed data of the 2019 National Road Network and the specific locations of the healthcare units as facilities. Using this base information, the tool generates a network that encom- 
passes all accessible streets that can be reached from the facility to a point in a given time.

\section{Results}

This paper aims to introduce a methodology that allows identifying the limited access to PHC units imposed using artificial road networks. Thus, not every aspect of the real accessibility of the PHC unit is considered in this paper (e.g., the assignation of people to PHC units, the size of the facilities, or the comparison with health providers other than the Ministry of Health), due to the lack of the information in public health systems in Mexico.

Table 2 summarizes data from 32 states that we used to select the four states for in-depth analysis. In 2015, according to the official data, Mexico had 119,530,753 distributed in 1,961,485 $\mathrm{km}^{2}$. While Chiapas, Oaxaca, and Guerrero coincide in some demographic indicators, including indigenous population, poverty level, and user of health services, Mexico City differs from those states' circumstances.

A series of isochrones ranging from 30 to 120 minutes was used when applying services area analysis to the study area to evaluate the effects of spatial access to PHC units to population, and because the reasonable distance people are willing to travel to visits health facilities may vary according to their age, social and economic status, and according to different types of care sought. Figure 1 shows the study area: Oaxaca is divided into 570 municipalities, and its capital city is Oaxaca de Juárez. Guerrero is divided into 81 municipalities, and its capital city is Chilpancingo. Chiapas is divided into 124 municipalities, and its capital city is Tuxtla Gutiérrez. Mexico City is the capital and largest city of Mexico and is divided into 16 subdivisions and the most populous city in North America.

\section{Spatial accessibility}

Spatial accessibility analysis for the four states selected (Oaxaca, Chiapas, and Guerrero) was performed with the Service Area Analysis. We measured the travel distance required to get to each PHC units of the Ministry of Health using the official road network, which has been mapped and shown in Figures 2, 3, and 4. Areas with higher accessibility to PHC units can be identified on each choropleth map indicating a different value on $\mathrm{km}^{2}$. The accessibility values have been classi- fied as low (120 or more minutes), medium (60 minutes), and high (30 min). Based on this classification, we can identify whether areas have access to PHC or not. The regions deprived of health care facilities are identified with any thematic color, and we decided to point to the locations in the state (most of them are rural).

The following observations can be made from the following figures. First, this method reveals more detailed spatial variation within a state on the access to PHC using the official road network and can graphically show the most deprived areas. Most of the locations shown in the maps are rural (as we previously mentioned). Second, the smaller the isochrone used, the higher the number of shortage areas identified.

Figure 2 shows that Oaxaca has several "deprived" spaces with many locations. It has the most significant proportion of indigenous people, who usually are dispersed. As the size of the isochrone increases in Oaxaca, we can see that access to PHC is present but a significant "divergence of access" appears in the largest area with access to PHC.

In all figures, we can see that the most significant variability of the access to PHC occurs at the most central part of the states, while bordering areas remain with the highest lack of access to PHC. The 30-minute travel time is often used as a reasonable distance for PHC units reported in the literature. Population located in areas with the higher time required to visit a PHC unit is suffering from the lack of spatial healthcare access and access to every location. Since we are using a road network, we can ascertain that people located in uncovered areas may not have access to basic services.

As we can see in Figures 3 and 4, the isochrone almost covers all the state. However, the level of access to PHC is divergent; while most of the areas within isochrone have 30 minutes of access on average, many areas have an excessively distant access to healthcare.

\section{Discussion}

States we selected for analysis coincide with an exceptionally large land area, event though, it is not necessarily related to a homogeneous concentration of the population, according to INEGI estimates, about $78 \%$ of the population is in urban areas (towns with more than 2,500 inhabitants) and the rest in rural $\operatorname{areas}^{28}$. The heterogeneous distribution of the population 
Table 2. Sociodemographic information of the 32 Mexican states, 2015, 2018, and 2020.

\begin{tabular}{|c|c|c|c|c|c|c|c|c|c|c|c|}
\hline State & 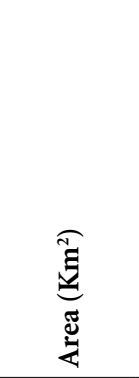 & 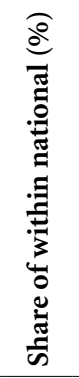 & 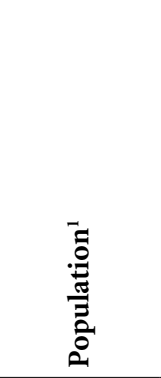 & 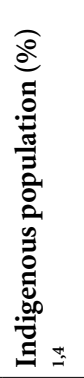 & 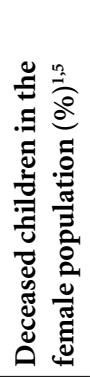 & 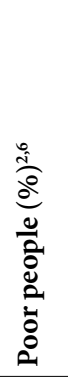 & 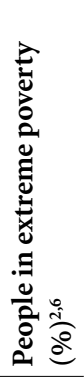 & 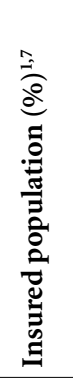 & 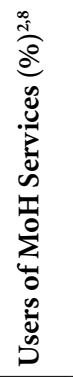 & 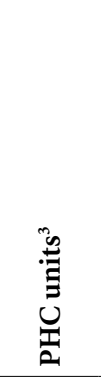 & 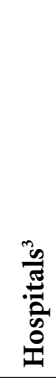 \\
\hline 01 Aguascalientes & 5,616 & 0.3 & $1,312,544$ & 0.3 & 5.5 & 26.2 & 1.2 & 63.7 & 37.3 & 108 & 7 \\
\hline 02 Baja California & 71,450 & 3.6 & $3,315,766$ & 1.5 & 4.9 & 23.3 & 1.6 & 66.3 & 30.3 & 188 & 9 \\
\hline 03 Baja California Sur & 73,909 & 3.8 & 712,029 & 1.5 & 4.8 & 18.1 & 1.5 & 68.9 & 32.5 & 83 & 7 \\
\hline 04 Campeche & 57,507 & 2.9 & 899,931 & 11.5 & 6.1 & 46.2 & 9.8 & 43.7 & 57.6 & 112 & 12 \\
\hline 05 Coahuila & 151,562 & 7.7 & $2,954,915$ & 0.2 & 5.4 & 22.5 & 1.4 & 80.2 & 17.5 & 175 & 15 \\
\hline 06 Colima & 5,627 & 0.3 & 711,235 & 0.6 & 6.2 & 30.9 & 2.4 & 56.5 & 43.2 & 153 & 6 \\
\hline 07 Chiapas & 73,311 & 3.7 & $5,217,908$ & 27.9 & 7.5 & 76.4 & 29.7 & 18.6 & 82.1 & 1030 & 49 \\
\hline 08 Chihuahua & 247,455 & 12.6 & $3,556,574$ & 2.7 & 6.2 & 26.3 & 2.6 & 64.5 & 31.8 & 270 & 20 \\
\hline 09 Mexico City & 1,495 & 0.1 & $8,918,653$ & 1.5 & 5.0 & 30.6 & 1.7 & 63.3 & 28.7 & 381 & 55 \\
\hline 10 Durango & 123,317 & 6.3 & $1,754,754$ & 2.4 & 6.9 & 37.3 & 2.2 & 55.4 & 45.9 & 248 & 27 \\
\hline 11 Guanajuato & 30,608 & 1.6 & $5,853,677$ & 0.2 & 6.7 & 43.4 & 4.2 & 41.7 & 58.5 & 583 & 45 \\
\hline 12 Guerrero & 63,596 & 3.2 & $3,533,251$ & 15.3 & 9.4 & 66.5 & 26.8 & 23.0 & 77.3 & 1009 & 43 \\
\hline 13 Hidalgo & 20,813 & 1.1 & $2,858,359$ & 14.2 & 7.2 & 43.8 & 6.1 & 32.3 & 68.4 & 539 & 24 \\
\hline 14 Jalisco & 78,588 & 4.0 & $7,844,830$ & 0.8 & 6.1 & 28.4 & 3.0 & 56.2 & 40.8 & 797 & 44 \\
\hline 15 State of Mexico & 22,351 & 1.1 & $16,187,608$ & 2.7 & 6.0 & 42.7 & 4.9 & 47.2 & 48.2 & 1224 & 71 \\
\hline 16 Michoacan & 58,599 & 3.0 & $4,584,471$ & 3.6 & 7.3 & 46.0 & 6.1 & 36.3 & 63.5 & 455 & 27 \\
\hline 17 Morelos & 4,879 & 0.2 & $1,903,811$ & 2.0 & 6.3 & 50.8 & 7.4 & 41.3 & 59.0 & 236 & 11 \\
\hline 18 Nayarit & 27,857 & 1.4 & $1,181,050$ & 5.4 & 7.2 & 34.8 & 5.9 & 51.8 & 51.4 & 267 & 13 \\
\hline 19 Nuevo León & 64,156 & 3.3 & $5,119,504$ & 1.2 & 4.3 & 14.5 & 0.5 & 71.0 & 20.1 & 477 & 13 \\
\hline 20 Oaxaca & 93,757 & 4.8 & $3,967,889$ & 32.2 & 9.2 & 66.4 & 23.3 & 23.0 & 78.3 & 911 & 39 \\
\hline 21 Puebla & 34,306 & 1.7 & $6,168,883$ & 11.3 & 8.1 & 58.9 & 8.6 & 29.7 & 69.4 & 707 & 53 \\
\hline 22 Queretaro & 11,699 & 0.6 & $2,038,372$ & 1.7 & 6.0 & 27.6 & 2.0 & 52.3 & 45.8 & 266 & 6 \\
\hline 23 Quintana Roo & 44,705 & 2.3 & $1,501,562$ & 16.6 & 5.0 & 27.6 & 3.5 & 58.6 & 40.7 & 207 & 12 \\
\hline 24 San Luis Potosi & 61,137 & 3.1 & $2,717,820$ & 10.0 & 7.1 & 43.4 & 7.3 & 43.3 & 57.7 & 301 & 16 \\
\hline 25 Sinaloa & 58,200 & 3.0 & $2,966,321$ & 1.4 & 6.0 & 30.9 & 2.7 & 60.7 & 39.8 & 307 & 24 \\
\hline 26 Sonora & 179,355 & 9.1 & $2,850,330$ & 2.4 & 5.2 & 28.2 & 2.6 & 68.4 & 30.1 & 481 & 18 \\
\hline 27 Tabasco & 24,731 & 1.3 & $2,395,272$ & 2.7 & 6.0 & 53.6 & 12.3 & 33.3 & 65.2 & 592 & 25 \\
\hline 28 Tamaulipas & 80,249 & 4.1 & $3,441,698$ & 0.7 & 5.3 & 35.1 & 3.3 & 58.1 & 39.3 & 361 & 27 \\
\hline 29 Tlaxcala & 4,016 & 0.2 & $1,272,847$ & 2.7 & 6.8 & 48.4 & 3.1 & 29.1 & 70.3 & 199 & 12 \\
\hline 30 Veracruz & 71,826 & 3.7 & $8,112,505$ & 9.2 & 7.6 & 61.8 & 17.7 & 40.0 & 59.7 & 839 & 60 \\
\hline 31 Yucatán & 39,524 & 2.0 & $2,097,175$ & 28.9 & 5.8 & 40.8 & 6.7 & 50.9 & 48.0 & 167 & 11 \\
\hline 32 Zacatecas & 75,284 & 3.8 & $1,579,209$ & 0.3 & 7.6 & 46.8 & 3.4 & 38.7 & 63.2 & 248 & 18 \\
\hline Total & $1,961,485$ & 100 & $119,530,753$ & 6.7 & 6.4 & 39.9 & 6.7 & 49.0 & 50.0 & 13,921 & 819 \\
\hline
\end{tabular}

Footnotes: 1. Data was obtained from the Intercensal survey 2015; 2. Data was obtained from poverty study from CONEVAL (Agency that measures poverty in Mexico) 2018; 3. Data was obtained from CLUES 2020; 4. Indigenous population are considered any who reports speaking an indigenous language with three or more years; 5 . This data represents the share of the female population with deceased children from the female population with children; 6. Poverty studies from CONEVAL use the multidimensional measurement of poverty, and classify into people in poverty, moderate poverty, and extreme poverty and take into consideration not only income but access to basic services, educational and backwardness; 7. Insured population refers to any people with affiliation to social security institutions; 8. Users of health services at Ministry of Health units in 2015.

Source: National Institute of Statistics and Geography (INEGI) 2015, National Council for the Evaluation of Social Development Policy (CONEVAL) 2019, National Catalogue of Health Facilities (CLUES) 2020. 


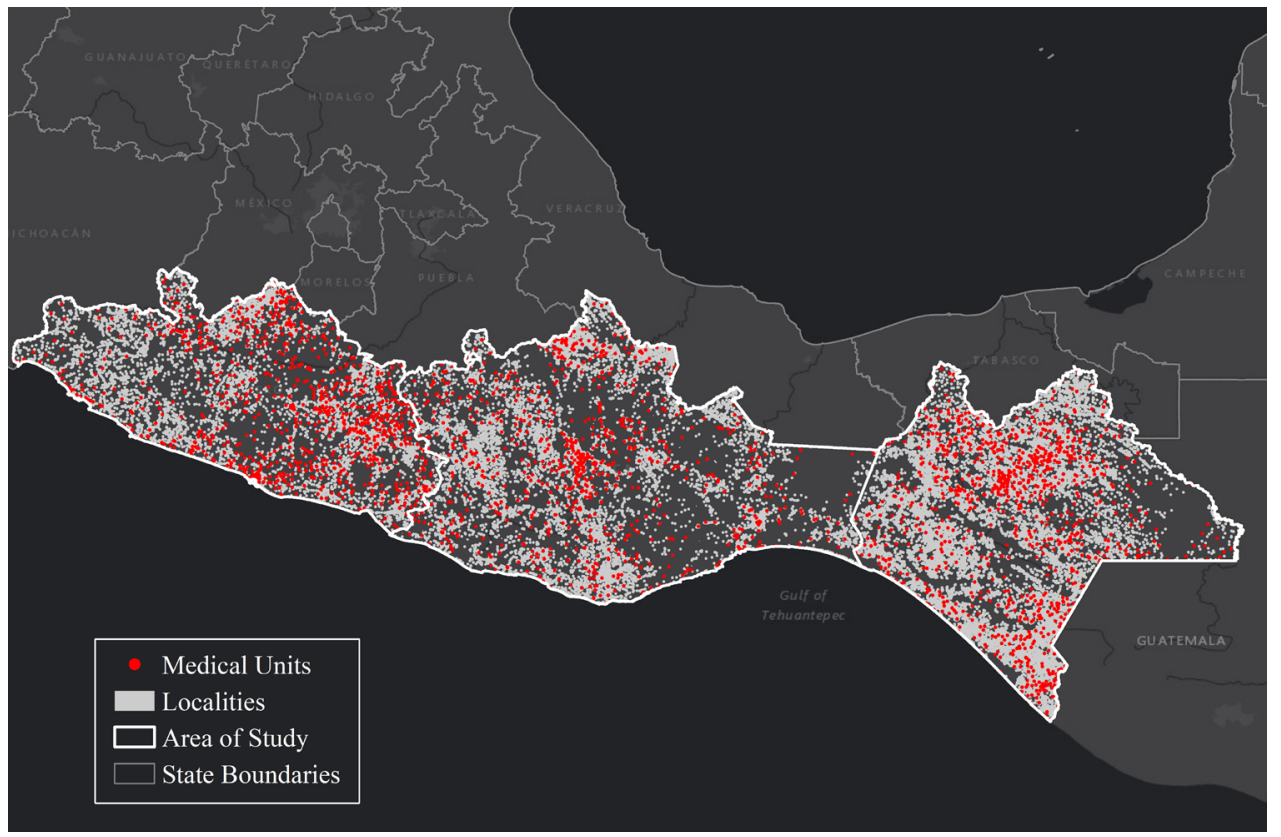

Figure 1. Boundaries of states selected for in-depth analysis (Guerrero, Oaxaca, Chiapas, and Mexico City).

Source: Esri, HERE, Garmin, (C)penStreetMap contributors, and the GIS user community.

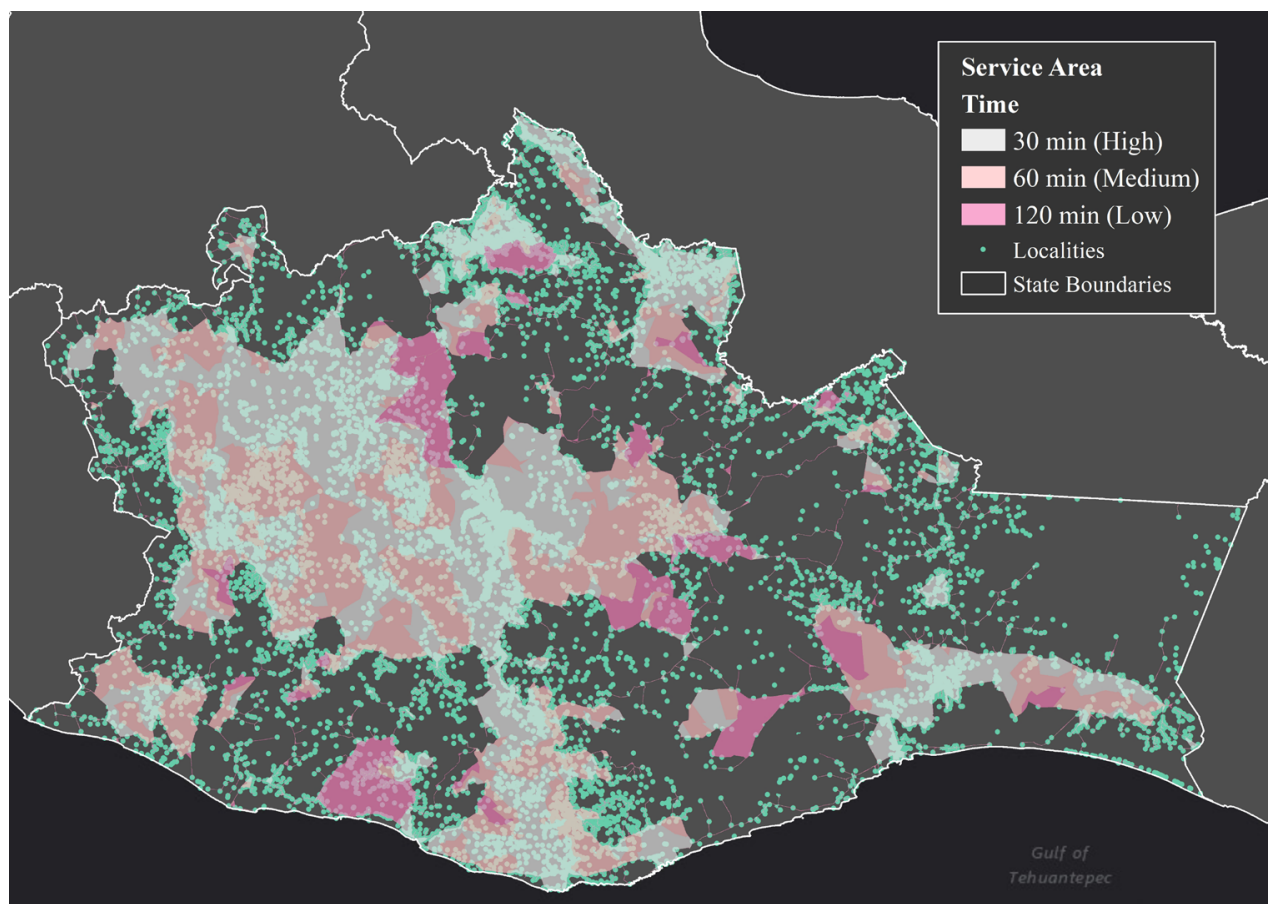

Figure 2. Service area coverage of Primary Health Care Units of the Ministry of Health in Oaxaca.

Source: Esri, HERE, Garmin, (@) OpenStreetMap contributors, and the GIS user community. 


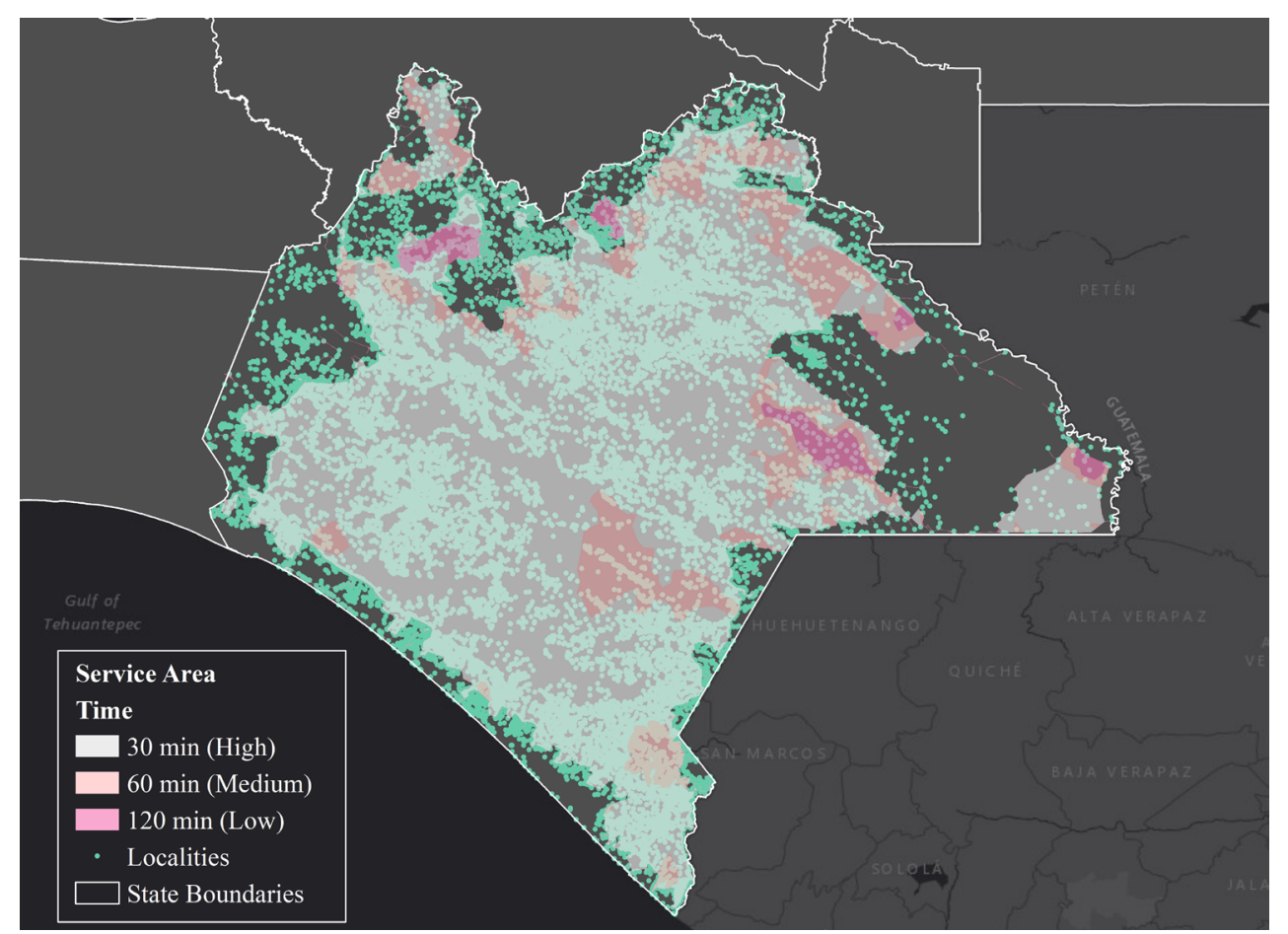

Figure 3. Service area coverage of Primary Health Care Units of the Ministry of Health in Chiapas. Source: Esri, HERE, Garmin, @O OpenStreetMap contributors, and the GIS user community.

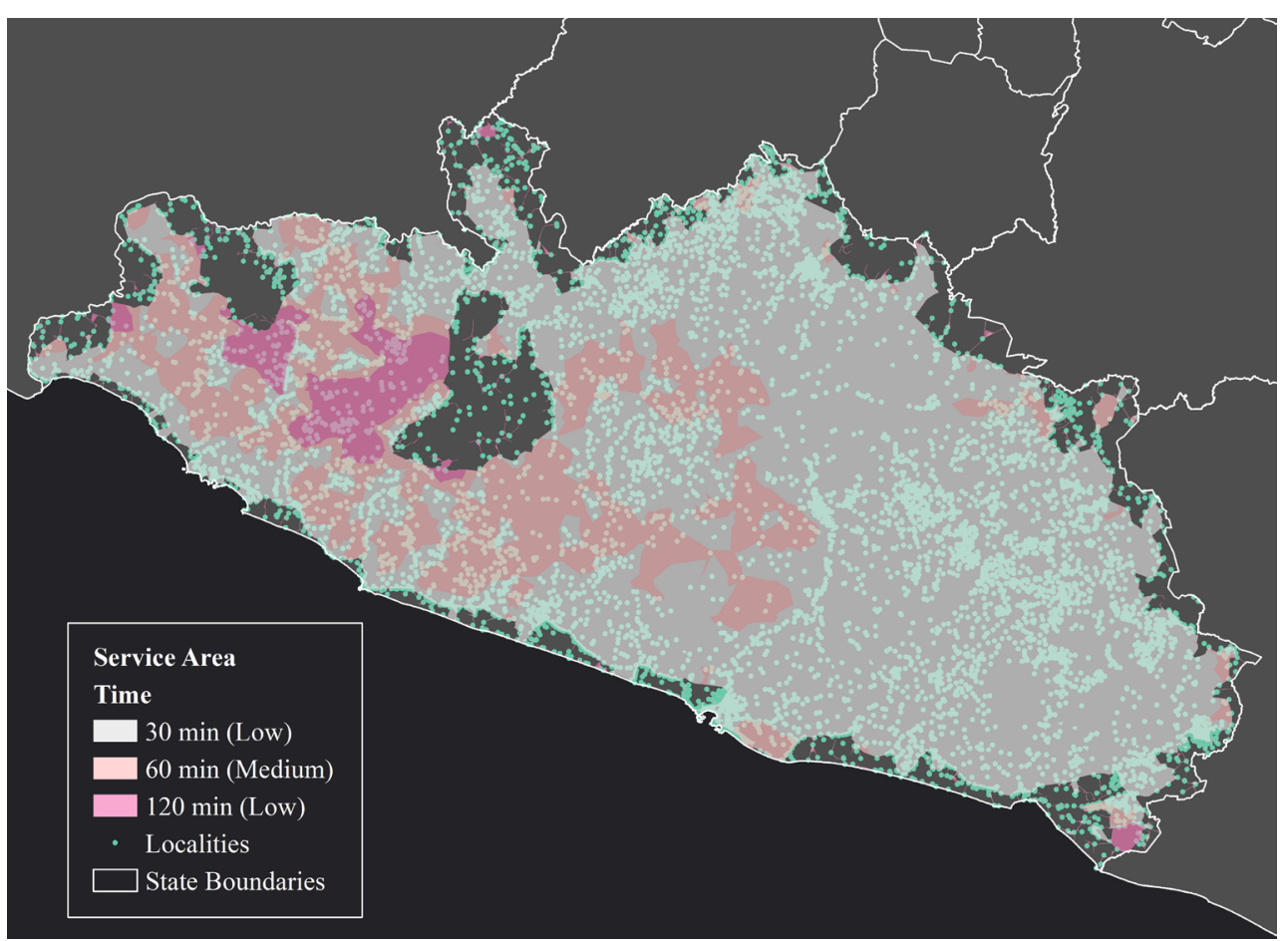

Figure 4. Service area coverage of Primary Health Care Units of the Ministry of Health in Guerrero. Source: Esri, HERE, Garmin, (COpenStreetMap contributors, and the GIS user community. 
creates significant challenges for the provision of health services, which suggests that people most adversely affected by poor access to PHC may have several other limitations, including access to other basic services, and other supplies, such as medications or medical equipment, may not be delivered to those most in need.

We should mention that the actual health care status for poor access areas may not be accurately reflected because we are not considering facilities of other providers. However, we decided not to include other providers because healthcare access depends on several other factors, such as affiliation.

During the last two decades, a significant number of PHC facilities were built using "Seguro Popular" financing, public health insurance covering a wide range of services without co-payment for its affiliates, to increase the health coverage to the population and supposedly achieve Universal Health Coverage in Mexico. The growing number of PHC facilities could be interpreted as continuous improvement in healthcare coverage (nominal access) to reduce distances from facilities to population. However, our analysis results (Figures 2, 3, and 4) show the real coverage of PHC facilities that remain with many underserved areas. An analysis with a comparison between geospatial coverage in 2000 and 2018 in the same states could provide further information on whether significant positive changes were achieved after PHC facilities' growth. Although this information is not included in this analysis, we can estimate that most of the PHC facilities were inaccurately planned (due to the lack of data), and many of them were located in places that did not respond to population needs.

Facility location is a critical element for health system performance, including $\mathrm{PHC}$ facilities and hospitals. Some research suggests that facilities' location plays a fundamental role in the success of programs, strategies, and health outcomes. In Mexico, the government does not perform further analysis to identify the most suitable public facilities near the population. Additionally, the spatial coverage of hospitals (distances) is a critical factor in health system performance. It takes on particular relevance for patient referral procedures. Ideally, a patient should attend a PHC facility primarily. If healthcare is not adequate, people are referred to hospitals to receive care. Unfortunately, in Mexico, patient referral procedures are not effective, and PHC facilities only provide a small package of preventive services, and hospitals are overcrowded with patients with preventable health problems (problems that can be solved in PHC facilities). This situation reduces the responsiveness of the hospital to solve real emergencies.

\section{Conclusions}

The use of GIS in the management and operational control of healthcare delivery has essential advantages: precise management of services distribution (family visits, immunizations, or palliative care), planning, and health services management. Medical emergencies for obstetric, traumatic events (referral system), and monitoring the distribution of supplies, medications, and immunizations with specialized tools. Different international experiences allow us to exemplify the advantages of this type of tool to confirm and improve healthcare service provision.

It is also required that tangible criteria based on geospatial principles are used during planning and design for the location of new facilities in order to improve health infrastructure and increase access to health services for the growing population, such as the geographical allocation of the rightful population, the redistribution of the population to the nearest existing units, and the productivity or saturation of Human Resources for Health.

The use of GIS is vital in the planning of health services infrastructure since it combines a series of studies that include spatial analysis of epidemiological and socioeconomic profiles, location of communication routes, risk analysis, the current situation of health services, population growth, among others, which allow to strategically select the places where the medical infrastructure will be built, with the corresponding provision of services required to respond population health needs.

Strategic resource allocation is essential for improving the efficiency and equity of the health system in Mexico. A thorough analysis of the current system is required, including exploring causes of poor performance to assess the potential role of GIS in achieving a more equitable and more efficient delivery system.

First, Mexico requires a national diagnosis of every state, including the use of GIS to identify underserved areas of health services. Once the starting point is established and reform objectives are clearly articulated, the role of strategic resource allocation in healthcare reforms can be defined. The diagnosis should explore municipality-level (or postal code-level) healthcare needs 
and their relationship with utilization patterns, incidence, prevalence, and mortality of diseases.

Second, Mexico should develop a mechanism to evaluate the population's specific health needs, considering spatial variables such as distance or road access. It is essential to consider adjustments for age and gender, and other demographic characteristics, to favor and support the most impoverished population. It is also essential to have a policy goal reflecting patient satisfaction with health services allocation.

Third, the mechanism of resource allocation development also involves large data requirements, strong analytical skills, and in-depth knowledge of the incentives in the allocation system in policymakers and technical staff. Health information systems in Mexico have several inaccuracies, duplication, or lacking data. Many health units do not even appear in official systems. Concerning geospatial information, the location of units uses several coordinate systems. Most of the errors are produced because people in charge of integrating data in states are not continuously trained by federal authorities of national agencies of health information systems (General Directorate of Health Information, in the case of the Ministry of Health). So, we strongly recommend improving data collection within states, develop virtual education strategies and incentives for people in charge of those tasks.
Finally, we can conclude that most inaccuracies in the allocation of health resources are strongly associated with inadequate Mexican information systems and the quality of procedures to allocate resources to most health providers. We just analyzed the Ministry of Health's situation, but we can assure that IMSS or ISSSTE have the same situation as seen with PHC facilities with overdemand of services, in contrast with others that are almost empty in certain hours. Therefore, we suggest that Mexican health authorities develop: a) Standards on the requirements of distance from population and road network (that can be applied in all the procedures of health providers), b) A national diagnosis of underserved areas with a focus on impoverished and indigenous people in order to prioritize them. Being "passive", expecting that the indigenous population travels several hours to PHC facilities promotes Mexico's inequality. c) We strongly encourage Mexican health authorities to strengthen the General Directorate of Health Information. A potential solution could be transforming it into a decentralized health information intelligence center with competencies such as collecting data of every health provider to produce accurate information at the most disaggregated level possible, with a strong inclusion of geographical data. 


\section{Collaborations}

Conceptualization: D Choperena-Aguilar, A Ramírez-Santiago and MC Acuña Díaz. Data curation: A Ramírez-Santiago. Formal analysis: D Choperena-Aguilar and A Ramírez-Santiago. Methodology: D Choperena-Aguilar and A Ramírez-Santiago. Project administration: D Choperena-Aguilar. Resources: D Choperena-Aguilar and A Ramírez-Santiago. Supervision: D Choperena-Aguilar, A Ramírez-Santiago and MC Acuña Díaz. Validation: D Choperena-Aguilar, A Ramírez-Santiago and MC Acuña Díaz. Visualization: D Choperena-Aguilar and A Ramírez-Santiago. Writing-original draft: D Choperena-Aguilar and A Ramírez-Santiago. Writing-review \& editing: D Choperena-Aguilar, A Ramírez-Santiago and MC Acuña Díaz.

\section{References}

1. Lapão LV, Arcêncio RA, Popolin MP, Rodrigues LBB. The role of Primary Healthcare in the coordination of Health Care Networks in Rio de Janeiro, Brazil, and Lisbon region, Portugal. Cien Saude Colet 2017; 22(3):713-724.

2. Lember M, Oleszczyk M, Pavlic DR, Svab I, Tedeschi P, Wilson A, Windak A, Dedeu T, Wilm S. The European primary care monitor: structure, process and outcome indicators. BMC Fam Pract 2010; 11(1):81.

3. Keya KT, Rahman MM, Rob U, Bellows B. Distance travelled and cost of transport for use of facility-based maternity services in rural Bangladesh: a cross-sectional survey. The Lancet 2013; 382:17.

4. Hawthorne TL, Kwan MP. Using GIS and perceived distance to understand the unequal geographies of healthcare in lower-income urban neighbourhoods. $J$ Geogr 2012; 178(1):18-30.

5. Buor D. Analysing the primacy of distance in the utilization of health services in the Ahafo-Ano South district, Ghana. Int J Health Plann Manage 2003; 18(4):293-311.

6. Escamilla V, Calhoun L, Winston J, Speizer IS. The Role of Distance and Quality on Facility Selection for Maternal and Child Health Services in Urban Kenya. J Urban Health 2018; 95(1):1-12.

7. Starfield B, Shi L, Macinko J. Contribution of Primary Care to Health Systems and Health. Milbank Q 2005; 83(3):457-502.

8. Macinko J, Starfield B, Erinosho T. The Impact of Primary Healthcare on Population Health in Low- and Middle-Income Countries. I Ambul Care Manage 2009; 32(2):150-171.

9. Organization for Economic Co-operation and Development (OECD). OECD Reviews of Health Systems: Mexico 2016. Paris: OECD Publishing; 2016.

10. Milliman Mexico Salud. Mexican Healthcare Model Reform. Mexico City: Milliman Global; 2004.

11. National Institute of Statistics and Geography (INEGI). Comunicado de prensa Núm.166/20 [Internet]. Mexico: INEGI; 2020. [cited 2020 Sept 12]. Available from: https://www.inegi.org.mx/contenidos/saladeprensa/aproposito/2020/trabajoNal.pdf

12. Office of Health Economics. Policy Options for Formulary Development in Middle-income Countries: Mexico Case Study. [document Internet]. London: OHE Consulting Ltd; 2017. [cited 2020 Sept 12]. Available from: https://www.ohe.org/system/files/private/publications/Mexico\%20case\%20study\%20Jan2017\%20 final\%20v2.pdf

13. Organization for Economic Co-operation and Development Statistics (OECD.Stat) [Online platform]: OECD, 2018[cited 2020 Sept 12]. Available from: https://stats.oecd.org/Index.aspx?ThemeTreeId=9

14. Hermanides RS, Kilic S, Van 't Hof A. Optimal pharmacological therapy in ST-elevation myocardial infarction-a review: A review of antithrombotic therapies in STEMI. Neth Heart J 2018; 26(6): 296-310.

15. Faridi KF, Peterson ED, McCoy LA, Thomas L, Enriquez J, Wang TY. Timing of First Postdischarge Follow-up and Medication Adherence After Acute Myocardial Infarction. JAMA Cardiology 2016; 1(2): 147-155. 
16. Wang S. A CyberGIS Framework for the Synthesis of Cyberinfrastructure, GIS, and Spatial Analysis. Ann Assoc Am Geogr 2010; 100(3):535-557.

17. Nykiforuk CIJ, Flaman LM. Geographic Information Systems (GIS) for Health Promotion and Public Health: A Review. Health Promot Pract 2011; 12(1):6373.

18. Salehi F, Ahmadian L. The application of geographic information systems (GIS) in identifying the priority areas for maternal care and services. BMC Health Serv Res 2017; 17:482.

19. Kim Y, Byon YJ, Yeo H. Enhancing healthcare accessibility measurements using GIS: A case study in Seoul, Korea. Plos One [serial on the Internet]. 2018 [cited 2020 Set. 12];13(2):e0193013 [about 10 p.]. Available from: https://doi.org/10.1371/journal.pone.0193013

20. Higgs G. A Literature Review of the Use of GIS-Based Measures of Access to Health Care Services. Health Serv Outcomes Res Method 2004; 5:119-139.

21. Yamashita T, Kunkel SR. The association between heart disease mortality and geographic access to hospitals: County level comparisons in Ohio, USA. Soc Sci Med 2010; 70(8):1211-1218.

22. Hare TS, Barcus HR. Geographical accessibility and Kentucky's heart-related hospital services. Appl Geogr 2007; 27(3):181-205.

23. Franch-Pardo I, Napoletano BM, Rosete-Verges F, Billa L. Spatial analysis and GIS in the study of COVID-19. A review. Sci Total Environ 2020; 739:140033.

24. McLafferty SL. GIS and Health Care. Annu Rev Public Health 2003; 24(1):25-42.

25. National Catalogue of Health Facilities (CLUES) [Internet]. Ministry of Health of Mexico 2020 Jul - [cited 2020 Sept 12]. Available from: http://www.dgis.salud. gob.mx/contenidos/intercambio/clues_gobmx.html

26. National Catalogue of Health Facilities (CLUES) [Internet]. Ministry of Health of Mexico 2020 Jul - [cited 2020 Sept 12]. Available from: http://www.dgis.salud gob.mx/contenidos/intercambio/clues_gobmx.html

27. National Catalogue of Health Resources [Internet]. Ministry of Health of Mexico. 2018 Dec. [cited 2020 Sept 12]. Available from: http://www.dgis.salud.gob. $\mathrm{mx} /$ contenidos/basesdedatos/da_recursos_gobmx. html
28. National Intercensal Survey 2015 [Internet]. National Institute of Statistics and Geography (INEGI) 2016 Jul - [cited 2020 Sept 12]. Available from: https:// www.inegi.org.mx/programas/intercensal/2015/default.html\#Microdatos

29. Results of Multidimensional Measurement of Poverty 2018 [Internet]. National Council for the Evaluation of Social Development Policy (CONEVAL) 2019 Aug - [cited 2020 Sept 12]. Available from: https://www. coneval.org.mx/Medicion/MP/Paginas/Programas_ BD_08_10_12_14_16_18.aspx _

30. National Geostatistical Framework 2019 [Internet]. National Institute of Statistics and Geography (INEGI) 2019 Dec - [cited 2020 Sept 12]. Available from: https://www.inegi.org.mx/temas/mg/

31. National Road Network 2019 [Internet]. National Institute of Statistics and Geography (INEGI) 2019 Dec [cited 2020 Sept 12]. Available from: https:// www.inegi.org.mx/app/biblioteca/ficha.html?upc= 889463776086

Article submitted 03/04/2020

Approved 07/08/2020

Final version submitted 09/08/2020

Chief editors: Maria Cecília de Souza Minayo, Romeu Gomes, Antônio Augusto Moura da Silva 